\title{
Women Empowerment in Lesotho: Reality and/or Myth?
}

\section{Kali M Kalimo*}

Pan African University, Cameroon

\begin{abstract}
This paper seeks to challenge the women empowerment policies in Lesotho. It posits that without the transformation of the socio-economic and political sphere, the mechanisms in place cannot lead to real women's empowerment. It is on this premise that the author suggests that the government of Lesotho needs to resolve the loopholes in the legal system and reconsider its approach and place resources at the disposal of women, in particular, to achieve equality and equity. Unless the laws are amended, until a decisive initiative is taken to reconcile the dilemma and contradiction between the constitution and customary laws and unless the government reinvigorate its commitment, women empowerment, though a reality, will not transcend mediocrity.
\end{abstract}

Keywords: Women empowerment and gender equality; Government strategies; Bureaucratic challenges and contradictions

\section{Introduction}

Even though women outnumber men, and concerted and commendable efforts are made to empower women, eradicate gender inequalities and strengthen women agency, their share of parliamentary membership worldwide is only $22.1 \%$ [1]. Most countries are yet to attain the global agreed quota of $30 \%$ [1]. This situation holds true for Lesotho, the focus of this paper. Gender representation is a concern in Lesotho because gender inequality still disadvantages women over men in all socio-economic and political spheres. Patriarchy, cultural norms, customs, religious practices; and both normative and structural discriminatory practices are usually the main factors that perpetuate gender inequality and mitigate empowerment, especially of women and girls.

However, Basotho women have not been passive about the above mentioned anomalies. They have engaged themselves in vigorous campaigns against gender inequality and gotten government attention. The Lesotho government, in the last three decades have ratified important global and regional gender based protocols and made attempt to domesticate some and modified state structures and policies such as the electoral system and adopted quotas to address the problem of gender gaps and increase women's representation in politics [2]. Worthy to note that a huge sum of public funds is allocated for gender issues; for instance, for the 2016/17 financial year M108.9 million was proposed for the Ministry of Gender, Youth, Sports and Recreation [3].

Nevertheless, the problem persists. Despite the 95\% female literacy rate, the implementation of gender protocols, mainstreaming of national policies, quotas, adoption of political party zipper/zebra list, women earn only $30.9 \%$ of the national income; women make up only $24.2 \%$ of the members of parliament and female ministers constitute only $22 \%$ of the ministers [1]. Furthermore, the degree of women political representation in the parliament is neither up to the minimum threshold of $30 \%$ set by the Beijing Plan of Action nor the $50 \%$ retained by the African Union [1].

\section{Statement of the Problem: Problems Associated With Ignoring Women Empowerment}

Strictly speaking, while government has made some strides as discussed in different sections of this paper, the achievements have not been attained within the set time frame. It is worthy to note that failure to achieve the set gender policy is costly and consequential to the state at large, the populace, especially women and children. For example, socially, more women than men suffer from development issues; the number of women living with HIV/AIDs is three times more than that of men [4]. Failure to empower women politically means that even gender-based violence which is still pervasive in Lesotho with at least $86 \%$ of the women experiencing it will not effectively subside [5]. Over and above, customary practices associated with inheritance of property still favour men over women [2]. Failure of government to achieve its gender goals implies that inequalities will continually disadvantage women hence sustainable development and women empowerment will be but a myth.

\section{Methodology}

The defaults of the empowerment strategies adopted by the government compel us to pose one critical question: Are Lesotho's gender empowerment approaches a reality and or a myth? Guided by this question, this paper endeavours to assess the contemporary approaches which include the Millennium Development Goals (MDGs) inter alia, which attempt to empower women. The paper is a product of desktop research and it employs content analysis to contend that real women empowerment does not result from merely increasing the number of women in parliament. It implies rather, the process of arming women with constitutional, material and financial resources to equip them to win elections without necessarily relying on men to put their names on party lists or voluntarily appoint them. The author is arguing that empowerment which does not achieve the above results remains largely a myth. The thrust of the discourse posits that the gender-based measures implemented by the government are not genuinely meant to empower women because they are mostly flawed and therefore until they are rectified they are but just a myth.

The paper first makes an attempt to conceptualise women's empowerment. Following that it discusses strategies the government adopted, their effects and limitations. This discourse then asserts that the government has never been interested in real empowerment of

*Corresponding author: Kali M Kalimo, Pan African University, Cameroon; E-mail: kalimoeketsi@gmail.com

Received May 18, 2018; Accepted June 20, 2018; Published June 27, 2018

Citation: Kalimo KM (2018) Women Empowerment in Lesotho: Reality and/or Myth? Arts Social Sci J 9: 373. doi: 10.4172/2151-6200.1000373

Copyright: @ 2018 Kalimo KM. This is an open-access article distributed under the terms of the Creative Commons Attribution License, which permits unrestricted use, distribution, and reproduction in any medium, provided the original author and source are credited. 
women hence why it has opted for placement of women on critical political posts without having empowered them to act autonomously. It concludes by suggesting measures that need to be implemented if the government is to achieve real women empowerment so that the efforts should go beyond sheer myth to reality.

The concept of women's empowerment focuses on their subjectivity and consciousness which signifies 'the power within' [6]. It also emphasizes the value of material and human resources that are necessary for women to exercise control over important aspects of their lives in order to manifest 'power to' by participating in the wider society. Together these components will help women to act collectively (to manifest the power with) to challenge and tackle the injustices they face. According to the Inter-American Development Bank women's empowerment connotes 'expanding the right, resources, and capacity of women to make decisions and act independently in social, economic and political spheres.' Similarly, the UN (2001) defined it in terms of: 'women's sense of self-worth; their right to have, and access opportunities and resources and determine their choices; their power to control their own lives inside and outside of the home; and their ability to have influence to create a just socio-economic order.' These definitions are crucial for this discourse.

Nonetheless, for this paper, we opt for the definition offered by Kabeer where women empowerment implies women having the capacity to manifest strategic control over their own lives [6]. It further demonstrates ability to renegotiate the relationships with others who matter so that women can participate in equal terms with men in societies in order to ensure a fair democracy and contribution to overall development. The author puts more emphasize on the expediency of material and non-material resources that are necessary for women's empowerment. The author challenges the inequality in the distribution of land, income, diseases, violence and the laws that disadvantage women over men. However, Lesotho has proven its commendable commitment to women empowerment notion in many ways.

\section{Literature Review: The Milestone of the Empowerment Process in Lesotho}

To start with, in an attempt to reverse the adverse effects of marginalization of women and in order to empower them, the government of Lesotho became a signatory to the following treaties and protocols: Convention on the Elimination of All Forms of Discrimination against Women (CEDAW) which was ratified on the 22 August 1995, MDGs and many other gender protocols. It also established the Ministry of Gender, Youth, Sport and Recreation in 2002 Government of the Kingdom of Lesotho [7].

Over and above these, the sexual offence Act 2003 was enacted by the government with the aim of combating sexual violence against women. Furthermore, the government adopted the Married Persons' Equality Act 2006 together with the 2008 National Plan on Gender Based Violence in order to preclude men from acting as if they own women and their property. Moreover, the Basotho Women's Parliamentary Caucus (BWPC) was established with the purpose of ensuring that all the legislation adopted by the parliament is gender sensitive. The function of the organ is to sensitise the policy makers on gender issues. Once more, Lesotho adopted a vast gender based policy framework dedicated to empowering women, be it as it may the political will still needs to be assessed with regard to the implementation. The assessment reveals that the successes of these policies are evident and notable in certain aspects.

\section{Concrete Initiatives of Women Empowerment in Lesotho}

First and foremost, Lesotho mainstreamed the laws to empower women. Section 30 of the National Assembly Act of 2011 mandates political parties registered with Independent Electoral Commission (IEC) to 'facilitate the full participation by women...in all political activities on the basis of equality' (National Assembly Act, 2011). All political parties in the country that contest for elections are required under proportional representation by the National Assembly Electoral Act 2011 to submit 'zebra' party lists to IEC; Section 47 (2) (b) states that political parties are supposed to ensure that they arrange candidates in terms of sex so that after every male or female is the opposite sex in the party list and (c) include equal numbers of women and men" (National Assembly Act, 2011). To this end, some political parties inter alia, Lesotho Democratic Congress (LCD) have adopted a policy which ensures that at least $30 \%$ of the members of its central committees on all other levels are women (Government of Lesotho, 2006:12).

Secondly, another product of the empowerment efforts is that women in parliament constituted $4.62 \%$ in the past before 1993 , whereas in recent years, women represented $25 \%$ in 2014 and $24.4 \%$ in 2016 [1]. Equally important, a woman - Nthloi Motsami was elected as the speaker of parliament for more than one term even though one suspects that she was placed there as a token woman for the government to claim its commitment on gender empowerment [8]. Last but not least, women ministers in recent years have increased so that they constituted $22 \%$ of the ministers in the country in 2015 . In the same way, the proportion of women in the local government councils soared so that in 2005 they constituted 58\% and in October 2011 they made up $49.1 \%$ of the councillors. These imply a positive effect of the gender empowerment policy which means that the dream of the government is being realised and so is becoming a reality.

Thirdly, literacy rate among women proves to have escalated so that it hit $95 \%$ as opposed to $83 \%$ of men [5]. This is a tremendous achievement albeit this may not unanimously be regarded as a product of the empowerment efforts from the government [2]. The achievement is rather attributable to the fact that Basotho men relegated education to women while they migrated to South African mines [2].

Owing to this plausible evidence, we can therefore say that Lesotho seems to be on track when it comes to empowerment of women in many aspects of life especially the education and political sphere. Apparently, due to this logic one can speculate that the gender policies in Lesotho are becoming a reality. However, there are a lot of loopholes that the government ought to rectify if its goals are to transcend a myth and become an indisputable reality. The aforementioned achievement is not worth celebrating for a number of reasons.

\section{The Hidden Tricks of Resisting Real Women Empowerment: Deprive Women of the Land}

First, land ownership and inheritance still favours men over women in Lesotho. While women are increasing in parliament, their sources of empowerment and resource base are still riddled with unnecessary errors, which can be explicated by feminism theory which undergirds this study, such unnecessary errors undermine the political will of the government. The land which could help women to be entrepreneurs to raise funds for political campaigns favours men. Studies have revealed that while a woman can now own land in Lesotho and inherit it upon the drafting of a will, under customary law first-born males are still the rightful heirs of land and family property [9]. Unless a decisive initiative 
is taken to draft a will women are naturally disadvantaged because the rightful heir will inevitably be the eldest son in the family. The other challenge is that the Land Act of 1979 was repealed by the Land Act of 2010 which adopted a gender neutral approach instead of a gendersensitive and gender-responsive stand so that the stereotypes of male chauvinism inculcated for decades can be reversed [9]. The problem we see in Lesotho is what Sara Longwe dubs the fallacy of subversion whereby the government is making little progress or sometimes no progress at all on its women empowerment goals [8]. Consequently, land allocation done through inheritance still favours men under customary practices.

Equally important, according to Mapetla, Lesotho Constitution and Bill of Rights application is contravened by the Land Act 1979 and the Deeds Registry Act 1967. Together the laws give women access to land and prohibit discrimination while at the same time taking the rights away from women to entrust to men. The interviews of the study revealed that in practice women still need the consent of men to buy land, sign or sell their land or for banks to give them loans even when the laws do not require it to be so. The study revealed that there is a vicious circle of land circulating around the hands of men. Consequently, in order for women to circumvent this practice they would keep the land they bought under their maiden names so that it would be easily inherited by their daughters without inevitably being inherited by the first-born males. The findings of the research established that in Lesotho women's access to land is constrained by factors embedded in the legal system. The other factor is the patriarchal system which has the tendency of entrusting land and property to males. Land is a critical resource that could be used to empower women if used well under capitalism.

Over and above that, research demonstrated that even though the legal capacity of Married Persons Act is in place, it may not be that effective in practice [10]. One study led by Braun in 2010 revealed that women were discriminated when they had to be compensated for their land which was used for construction by the Lesotho High Lands Water Project [10]. The fallacy of illusion is evident in the country because the government is convinced that laws are no longer discriminatory yet in practice women's development issue is diluted to the level of practical needs and access to strategic needs is still hampered $[8,11]$. The study discovered that compensation for land was solely paid to men, whereas women's claim for their lost land was disqualified. This incident, according to the study, served to illustrate the prevailing gender inequalities in Lesotho amidst the empowerments efforts and high rhetoric. Things may be changing at a satisfying pace in town but in the villages it is but a pity. It is as if the government's hand is too short to reach the remote areas of Lesotho. As if making land-ownership the privilege of men was not enough to perpetuate women's dependency on men in the socio-economic sphere, men found many other ways of maintaining their superiority over women.

\section{Relegate Women to the Non-Strategic Posts}

Apart from the land, the other resource bases that women have at their disposal are the government jobs and entrepreneurship base. Nevertheless, even though the laws have endeavoured to ensure equal opportunities for all, women's economic empowerment is still lagging behind. Studies established that in 2011 women in Lesotho earned just $30.9 \%$ of the national income while men contributed $69.1 \%$ and the inequality income gap that favours men over women was recorded at $47 \%$ in 2015 [12]. This implies that women occupy non-strategic positions or do less paying activities in order to meet their practical needs and this notion is dubbed a fallacy of selection because if not there would not be a huge gap of incomes between the two sexes, especially because women are more literate than men in Lesotho [8].

Women in Lesotho are mostly employed in the textile and apparel industries where they earn extremely meagre salaries. Being a politician is a costly endeavour that needs more than the insignificant factory salaries. On the other hand, studies discovered that in Lesotho women contributed only $59.2 \%$ to labour force participation rate while men made up $73.9 \%$ [12]. The observation is that women are more than men in Lesotho but their participation rate in the labour sector is relatively low and their total income is also low while that of men is relatively higher. Under these circumstances it is implied that even fewer women would be empowered. In fact, under this circumstance, many women would depend on men for survival and thus they would be tactically disempowered as though they were ill.

\section{Marginal and Non-Substantive/Tokenised Support to Maintain the Status Quo}

Other factors that undermine the results of empowerment of women in the country are attributable to diseases and rampant violence among women. Violence and diseases particularly HIV/AIDS are devouring Basotho women to an extend that one may erroneously speculate that the government is not doing enough to assist women so as to maintain their subordinate status. It has been established that HIV prevalence in Lesotho is nearly three times higher in women for it is $14.2 \%$ while it is rated at $5.4 \%$ among men [4]. In spite of the Sexual Offence Act 2003, rape is still high in Lesotho to an extent that at least 92 out of 100,000 women are raped annually and 35\% of married women admitted that they once experienced marital rape [5]. Some women do not have power individually; power within is lacking so that they cannot voice out and speak out against domestic violence. Despite the efforts made and the ratified protocols, in respect to gender violence, Lesotho ranks 57 globally and this is far from good (Global Gender Gap Report, 2016). HIV/AIDS and domestic violence undermine women's power to act and so long as they remain widespread in the country the empowerment process remains dubious at best.

\section{Emphasize Masculinity in the Legal System and Ignore Women}

The empowerment efforts in Lesotho are a myth because the government is blinded by what Longwe refers to as the fallacy of inversion [8]. This is so simply because attempts are made to encourage women to participate in politics whereas the laws are not gender sensitive. If the government's women empowerment effort is genuine it could have long amended the constitution to empower women. According to Brody policies and legislation are supposed to address differing needs, priorities, interests and responsibility of both sexes and their unequal economic and social power and establish clear gendered understanding of government [13]. However, the Lesotho constitution is not gender sensitive for it uses a masculine language and tends to ignore females. Section (4) (1) of fundamental human rights and freedoms reads "Whereas every person in Lesotho is entitled, whatever 'his' race, colour, sex..." and section (5) (1) reads "...No one shall be arbitrarily deprived of 'his' life." Ignoring the other gender in the fundamental legal framework and foundation of the laws of the nation may spell disaster for women if it has not done so already.

\section{Act Incompetently Towards the Empowerment Process}

The other challenge which is close to the fallacy of compartmentalisation posited by Longwe is attributable to the 
formation of the Ministry of Gender, Youth, Sports and Recreation [8]. The conflation of gender issues with youth and sports has the propensity to undermine the empowerment efforts. The budget allocated for gender issues cannot easily be accounted for because it has to deal with four different issues - gender, youth, sports and recreation. For instance, the 2016/17 financial budget of M108.9 million was proposed for the aforementioned ministry without a clear partition of the budget into the four areas [3]. Treating gender as a standalone with highly competitive sectors demanding much attention (such as youth and sport concerns) often lead to tokenism and marginalisation of gender issues; administratively, it can lead to fade away of gender concerns in management.

\section{Women Empowerment: The Reality and Myth Debate}

The analysis so far reveals that government efforts are imperfect and conflictive. For example, what premise is used by the constitution of Lesotho to view and exempt customary law from being non-discriminatory? The viewpoint that customary law is nondiscriminatory not only works against women empowerment but incapacitate the constitution and other related actions from achieving women's empowerment. It might become impossible to attain women empowerment, let alone at the control level [2]. Likewise- traditional practices tied to land allocation still advantage men over women. Other problems that disempowered women and or disenable women to compete on equal basis with their men colleagues such as health and reproductive rights issues, land rights, property rights, gender-based violence and conflation of women's ministry with too many issues have received little or no attention from the government. The situation is further exacerbated by gender inequality in access to and control over economic resources such as government jobs and land assets which favour men over women, render most women disempowered and unable to compete on equal basis with men. These circumstances do not foster gender equality and equity; it becomes extremely difficult to achieve them, including women's empowerment.

It is against this backdrop that we discover the futility of quotas, electoral system, the ratified gender protocols, and amendment of the constitution in order to usher the women class into parliaments. The quotas and placement done by the Lesotho political parties to combat underrepresentation of women do not empower women or change the patriarchal structure; at best they are meant to curb the extreme effects of underrepresentation of women. What is necessary is a radical transformation that will fully emancipate women from male dominance. By radical transformation I mean measures that could ensure that women freely canvass and campaign without distractions from laws and men; and putting in place rules and regulations that are gender-responsive and not rules of the game that allow men to dominate parliamentary activities and procedures. The fact that Lesotho is patriarchal and men believe that they are superior to women aggravates the misery of women and so the society at large is the main anchor of the gender stereotypes. The flaws exposed in this discourse compel one to believe that the policy approach and strategy aimed at promoting women's empowerment in Lesotho is a myth and an ideal which the government is unable to attain.

On the other hand, the criticisms that quotas, change of electoral model, amendment of policies are not effective approaches to women empowerment are misplaced. The aforementioned arguments are superficial because empowerment of women, an expected gain associated with increasing the proportion of women in the political sphere, and fast-tracking the amendment and ratification of rules/laws/ protocols are some of the fundamental and most essential ingredients in the empowerment process. The criticisms are unfounded because real empowerment requires the government to act in tandem with women, private sector and the society to empower women otherwise assuming that it is the monopoly of government to empower women is a misconception. Owing to the lack of rigour in this discourse that undermines the achievements of the government on the subject of women empowerment the author asserts that the empowerment process in Lesotho is not without faults nonetheless it is without doubt a reality due to a good number of reasons.

First, Lesotho has not only signed gender based treaties but has also domesticated them. Second, the government has amended the laws to ensure that women who at one point could not own land now can not only access but also have control over land. Third, the government has imposed gender quotas on political parties through the Independent Electoral Commission. Fourth, Lesotho has seen a relatively gradual increase of women in parliament, cabinet and local government. Lastly, the government has created a women ministry dedicated to women affairs. It is therefore fair to conclude that in spite of the flaws encountered in the implementation of the empowerment policies, the process is a reality in Lesotho. The author recognizes that the process can be bolstered and improved by bringing in a few changes to perfect it such as the separation of gender issues from sports and recreational issues and ensuring that the banks, among other institutions, give women loans just as the law requires and not as the custom has always been at the time when a woman could not access a loan without the approval of a husband. If the government ameliorate the status of women by ensuring strict implementation of the already existing policies and modification of the flawed laws such as the dilemma between the constitution and the customary law the empowerment process will be indisputable.

In spite of the legal shortcomings women in Lesotho have benefited a lot from the empowerment process. Socially, throughout primary and secondary schools more women than men enrol for education and this scenario is not so common in other Sub-Saharan countries. Equally important, adult literacy stands at $95 \%$ for women while it is at $83 \%$ for men. Again, Lesotho is ranked one by the World Economic Forum on gender educational attainment, one on health and survival, 66 on economic participation and opportunity and 70 on political empowerment in the world [14]. Politically, the number of women ministers and legislatures increased significantly and a woman became the speaker of parliament for more than one term [14]. Moreover, for the first time a woman formed a politically party and made it to parliament.

The civil society organizations such as the Christian Council of Lesotho, Transformation Resource Centre, inter alia, have contributed a lot to these accomplishments women made. They helped awaken, sensitise and educate women about their rights $[15,16]$. They used the media especially the radio stations to eradicate the gender stereotypes in society. Nonetheless, there remains something to be done to consolidate the empowerment endeavour. The organisations have not gone to the grassroots level and rarely penetrate to the remote areas of the country where the radio stations can hardly broadcast. The civil societies' public outreach is skewed and in most cases it is limited to the lowlands and is very rare at the highlands of the country. Due to these defects and shortcomings of the government and civil societies, there are things that still have to be done for the empowerment endeavour to be a success beyond any iota of doubt. 


\section{Recommendations}

In order to transcend the myth of empowerment and ensure an indisputable women empowerment process the government of Lesotho should first correct the faults in the system that disadvantage women against their male counterparts. Firstly, there should be reconciliation between Land Act 1979 and the Deeds Registry Act 1967 together with the customary practices pertaining to ownership of land so that women are treated fairly in regard to land and property inheritance $[17,18]$. This will increase the number of women who have access and control over land and curb the practice of having land circulating in men's hands. Secondly, the government and non-governmental organisations (NGOs) should form a synergy dedicated to empowering women, protecting their rights, supporting their economic base and assisting aspiring women politicians with nonmaterial resources to make their political endeavour a success. Thirdly, the government and NGOs should hold seminars on women leadership to equip women for political posts and sensitise women and men of the necessity of women leadership and the need to eradicate gender stereotypes and violence [19]. Finally, IEC, NGOs and the state should allocate material resources at the disposal of women candidates to facilitate their political rallies and campaigns - this could be done as an affirmative action. This will act as a catalyst to curb the long standing income inequalities between women and men. If all these could be done, the empowerment efforts implemented in the country would naturally transcend myth and become indisputable reality.

\section{Conclusion}

The discussion in this paper demonstrated that cultural, economic, social, political and legal factors play a significant role in obstructing Basotho women's empowerment and in turn their access to parliament. In particular, access to land, inheritance process, customary law and the legal system favours men over women; these elements promote the feminisation of disempowerment of women and limit the state's ability promote and achieve high rate and level of women empowerment and gender equality. Nonetheless, the paper revealed that women empowerment in Lesotho in some ways is a reality and not a myth, even though the process is flawed and hampered by structural contradictions in the laws, legal systems and socio-cultural barriers. If an expedient intervention is taken to address all these concerns, the promotion and attainment of gender empowerment policies will not be disputable.

\section{References}

1. Inter-Parliamentary Union (2016) Inter-Parliamentary Union for Democracy for Everyone. Women in Parliament in 2015: The year in Review. InterParliamentary Union: The Canadian Press.
2. Francis M (1997) Gender and Politics: A Note on Gender Inequality in Lesotho. Journal of Social Development in Africa 12: 5-14.

3. Mamphono K (2016) Managing Public Finances in Challenging Economic Times. Budget speech to parliament for the 2016/2017 fiscal year.

4. Lesotho Country programme document 2013-2017 (2012) The draft programme document for Lesotho (E/ICEF/2012/P/L.8) presented to the Executive Board for discussion and comment at the 2012 session.

5. UNDP (2015) Lesotho National Human Development Report: Summary 2015. Leveraging the Power of Youth to Promote Human Development. United Nations Development Programme.

6. Naila K (2012) Women's economic empowerment and inclusive growth: labour markets and enterprise development. SIG WORKING PAPER 2012/1School of Oriental and African Studies, UK.

7. Ministry of Gender, Youth, Sports and Recreation (2004) Lesotho Report Beijing +10 Preparation. Luzaka Zambia.

8. Sara HL (1990) From Welfare to Empowerment' Office of Women in International Development, Working Paper 204, Michigan State University.

9. Palesa M (2006) Gender Stereotypes and Education in Lesotho. A thesis submitted to the department of philosophy and policy studies in education at the University of Free State Bloemfontein.

10. Braun YV (2011) Left High and Dry: An Intersectional Analysis of Gender, Dams, and Development in Lesotho. International Feminist Journal of Politics 13: 141-162.

11. Caroline M (1989) World Development. Gender Planning in the Third World: Meeting Practical and Strategic Gender Needs 17: 179-185.

12. Human Development Report (2016) Human Development for Everyone: Briefing note for countries on the 2016. Human Development Report Lesotho UNDP.

13. Alyson B (2009) Gender and Governance: Overview Report. Institute of Development Studies. University of Sussex.

14. Global Gender Gap Report (2015) Global Gender Gap Report 2015: 10th Anniversary Edition. Geneva: World Economic Forum.

15. Government of Lesotho (2006) Lesotho Report: African Union Solemn Declaration on Gender Equality in Africa.

16. Inter-American Development Bank (2010) Operational Policy on Gender Equality in Development Washington: Inter-American Development Bank.

17. Women in politics: 60 years in retrospect (2000) Background paper prepared by the IPU for the United Nations Expert Group Meeting on "Equal participation of women and men in decision-making processes, with particular emphasis on political participation and leadership.

18. Kabeer N (2008) Paid work, women's empowerment and gender justice: critical pathways social change. Pathways Working Paper Brighton: IDS.

19. National Assembly Act of 2011 Suppliment No.1. to Gazzete No. 61 of $26^{\text {th }}$ August 2011. Part V - Nomination of the candidates: Party Lists. 